\title{
Estudo fenológico de Bactris gasipaes Kunth, Euterpe edulis Mart. e Syagrus romanzoffiana (Cham.) Glassman no Vale do Ribeira, SP, Brasil ${ }^{1}$
}

\author{
Valéria Augusta Garcia ${ }^{2,3}$ e Cláudio José Barbedo²
}

Recebido: 1.06.2015; aceito: 2.02 .2016

\begin{abstract}
Phenology of Bactris gasipaes Kunth, Euterpe edulis Mart. e Syagrus romanzoffiana (Cham.) Glassman in the Vale do Ribeira, São Paulo State, Brazil). Aiming at understanding the biology, life cycle and temporal occurrence of the vegetative and reproductive phases of three palm trees, Bactris gasipaes, Euterpe edulis and Syagrus romanzoffiana, in the Ribeira Valley, São Paulo, we recorded the occurence of their flowering, fruiting, leaf fall and leaf flushing. In our 2-year study we observed 15 individuals of each species and vegetative and reproductive events were registered fortnightly. Two reproductive events were observed and they occurred once a year, however differing in reproductive intensity among species and, in the same species, from one year to another. Ripe fruits were observed for a long period (seven consecutive months) even when both precipitation and temperature were low. Bactris gasipaes showed an average of 147 days from the floral spathe opening to the development of ripe fruit, while for Euterpe edulis this process took 280 days, and 174 days for Syagrus romanzoffiana
\end{abstract}

Keywords: Arecaceae, queen-palm, juçara-palm, peach-palm

RESUMO - (Estudo fenológico de Bactris gasipaes Kunth, Euterpe edulis Mart. e Syagrus romanzoffiana (Cham.) Glassman no Vale do Ribeira, SP, Brasil). As informações fenológicas permitem compreender a biologia das espécies, o seu ciclo vital e sua ocorrência temporal. Objetivando avaliar os eventos fenológicos das palmeiras Bactris gasipaes, Euterpe edulis e Syagrus romanzoffiana, no Vale do Ribeira, São Paulo, foram registradas quinzenalmente as fenofases de 15 indivíduos representando cada espécie, durante 24 meses. Dois eventos reprodutivos foram observados, e ocorreram como um evento singular anual, com variações na intensidade reprodutiva entre as espécies e de um ano para outro. A presença de frutos maduros por até sete meses consecutivos, evidenciou-se como uma fenofase duradoura, com disponibilidade inclusive em período com precipitação e temperatura baixas. Em Bactris gasipaes, o processo durou 147 dias desde a abertura da espata floral até o desenvolvimento de frutos maduros, já em Euterpe edulis esse processo demorou 280 dias, enquanto em Syagrus romanzoffiana a duração foi de 174 dias.

Palavras-chave: Arecaceae, fenofase, jerivá, juçara, pupunha

\section{Introdução}

O sucesso da reprodução e do potencial de dispersão determina a capacidade de sobrevivência das espécies vegetais, podendo afetar a sua distribuição, abundância e especificidade de habitat (Ranieri et al. 2012). Assim, a adaptação do período de produção das sementes pode estar relacionada a atividade de polinizadores e dispersores, ao desenvolvimento do fruto e da semente, ao comportamento de predadores de sementes e às necessidades específicas para a germinação (Janzen 1976).
Os estudos fenológicos podem colaborar para o melhor entendimento sobre o processo de desenvolvimento e dispersão dos frutos, e ainda permitem a previsão da época de reprodução e caracterização desse processo, possibilitando determinar estratégias de coleta de sementes e disponibilidade de frutos (Alencar 1994, Jardim \& Kageyama 1994). De acordo com Rathcke \& Lacey (1985), o termo fenologia tem origem da palavra grega phaino, que significa mostrar ou aparecer, podendo ser definido como o estudo da ocorrência das fases ou atividades do ciclo vital das plantas e

1. Parte da Tese de Doutorado do primeiro Autor

2. Instituto de Botânica, Av. Miguel Stéfano 3687, 04301-902 São Paulo, SP, Brasil

3. Autor para correspondência: val.garcia@uol.com.br 
sua ocorrência temporal ao longo do ano, permitindo a compreensão da biologia das espécies, possibilitando o entendimento do seu ciclo vital e sua ocorrência temporal (Lieth 1974, Alencar 1994).

A análise dos eventos fenológicos dos ecossistemas florestais é abordada basicamente de duas formas: caráter qualitativo, onde são levantadas as épocas em que ocorrem as fenofases, medidas em termos de atividade; e caráter quantitativo, onde as fenofases são também medidas em termos de intensidade do evento (Fournier 1974, Bencke \& Morellato 2002, D’Eça-Neves \& Morellato 2004). Cada estágio fenológico é denominado de fenofase, e se caracteriza por mudanças externamente visíveis nos indivíduos. Existem quatro principais fenofases consideradas nos estudos com vegetais: queda de folhas, folhas novas, floração e frutificação (Antunes \& Ribeiro 1999).

Em muitas florestas neotropicais, as palmeiras destacam-se pela abundância e riqueza de espécies, tanto no sub-bosque quanto nos estratos superiores e estão entre as plantas de maior longevidade no reino vegetal, desempenhando, assim, papel importante na estrutura e funcionamento de diversos ecossistemas e na sucessão ecológica (Reis \& Kageyama 2000, Bernacci et al. 2006).

As palmeiras são frequentemente consideradas "espécies chave" por possuírem pouca sincronia e longos períodos de frutificação, o que torna seus frutos disponíveis em épocas de escassez geral de frutos, sendo importante recurso alimentício para frugívoros tropicais (Galetti et al. 1992, Galetti \& Aleixo 1998, Henderson et al. 2000, Galetti et al. 2006).

De acordo com Castro et al. (2007), pouco se sabe sobre os padrões de reprodução das palmeiras, apesar de sua importância, estudos fenológicos são escassos e as informações generalizadas. Assim, o objetivo deste trabalho foi avaliar os eventos fenológicos das palmeiras Bactris gasipaes Kunth, Euterpe edulis Mart. e Syagrus romanzoffiana (Cham.) Glassman, no Vale do Ribeira/SP, visando a ampliar o conhecimento sobre as estratégias de sobrevivência e a ocorrência das fenofases.

\section{Material e métodos}

Área de estudo - A pesquisa foi conduzida no Pólo Regional de Desenvolvimento Sustentável dos Agronegócios do Vale do Ribeira (PRDSAVR) APTA, localizado na Rodovia Regis Bittencourt, km 460 (BR-116), município de Pariquera-Açu, Estado de São Paulo (2436'31" S e 47053'48"O, a 25 metros s.n.m).
A região do Vale do Ribeira apresenta, segundo a classificação de Köppen, os tipos climáticos Cfa, $\mathrm{Cfb}$ e Af: quente/úmido com temperaturas inferiores de $18{ }^{\circ} \mathrm{C}$ no mês mais frio e superiores a $22{ }^{\circ} \mathrm{C}$ no mês mais quente. Durante o período de observação fenológica, de fevereiro de 2011 a janeiro de 2013, foram coletados os dados meteorológicos da Estação Climatológica de Pariquera-Açu (SP), localizada no próprio PRDSAVR, e disponibilizados pelo Centro Integrado de Informações Agrometeorológicas (CIIAGRO) (figura 1).

Espécies e avaliações - Três espécies de Arecaceae, Bactris gasipaes, Euterpe edulis e Syagrus romanzoffiana foram avaliadas do ponto de vista fenológico no período de fevereiro de 2011 a janeiro de 2013. Para cada uma delas foram selecionados 15 indivíduos adultos e avaliados quinzenalmente (figuras 2, 3 e 4). Suas copas foram observadas a olho nu e também, com o auxílio de binóculos, registrando-se a presença ou ausência dos eventos de florescimento (espata floral e floração), frutificação (cachos com frutos imaturos e maduros) e a quantidade de estruturas reprodutivas (espata floral, floração e frutificação), presentes em cada indivíduo, de acordo com Frankie et al. (1974) e Morellato et al. (1989).

Para a fase de espata floral considerou-se o período em que a inflorescência manteve-se coberta por brácteas. Já com relação a duração da fase de floração considerou-se desde a abertura da espata, presença dos botões florais, até a queda das flores. Enquanto a duração da fase de fruto imaturo foi considerada a partir da visualização dos primeiros e pequenos frutos em formação, até o início do seu amadurecimento. Já a fase de fruto maduro considerou-se a partir da visualização dos primeiros frutos maduros ainda na infrutescência, até sua queda total.

Para a mudança foliar, considerou-se como folha nova a que ainda se apresentava totalmente fechada, já as que se apresentavam verdes e abertas foram denominadas maduras, e como folha velha as secas aderidas à planta.

Utilizou-se o método de análise de caráter quantitativo em nível populacional, que indica a porcentagem de indivíduos da população observada que manifestou determinado evento fenológico, onde quanto maior o número de indivíduos manifestando determinado evento, maior será a sincronia da população (Morellato et al. 1990, Bencke \& Morellato 2002). Para tanto, foi empregado o índice de atividade (IA) ou porcentagem de indivíduos: 
$\mathrm{IA}=100 .\left(\right.$ nif.nti $\left.^{-1}\right)$, onde nifé o número de indivíduos na fenofase e nti o número total de indivíduos observados.

Foi considerado evento fenológico não sincrônico ou assincrônico quando $<20 \%$ de indivíduos encontravam-se na fenofase; pouco sincrônico ou sincronia baixa com $20-60 \%$ de indivíduos na fenofase e sincronia alta com $>60 \%$ de indivíduos na fenofase (Bencke \& Morellato 2002).

Apesar de terem sido marcadas 20 estruturas reprodutivas de diferentes plantas para a contagem de tempo de formação dos frutos, consideraram-se apenas 12 para a realização dos cálculos, tendo em vista as perdas que ocorreram durante o processo de maturação causadas por vento, pragas e doenças.
As plantas, além de marcadas, foram fotografadas semanalmente, e monitoradas até a visualização de frutos completamente maduros, quando se considerou finalizado o processo de maturação.

\section{Resultados e Discussão}

Fenologia de Bactris gasipaes - As matrizes apresentaram atividade reprodutiva durante quase todo período de observação ( 24 meses), exceto no mês de outubro do ano de 2011 e em setembro de 2012 (figura 5).

No verão, época mais quente do ano e com maior precipitação, houve pico de produção das espatas florais. A primeira frutificação, que ocorre anualmente,
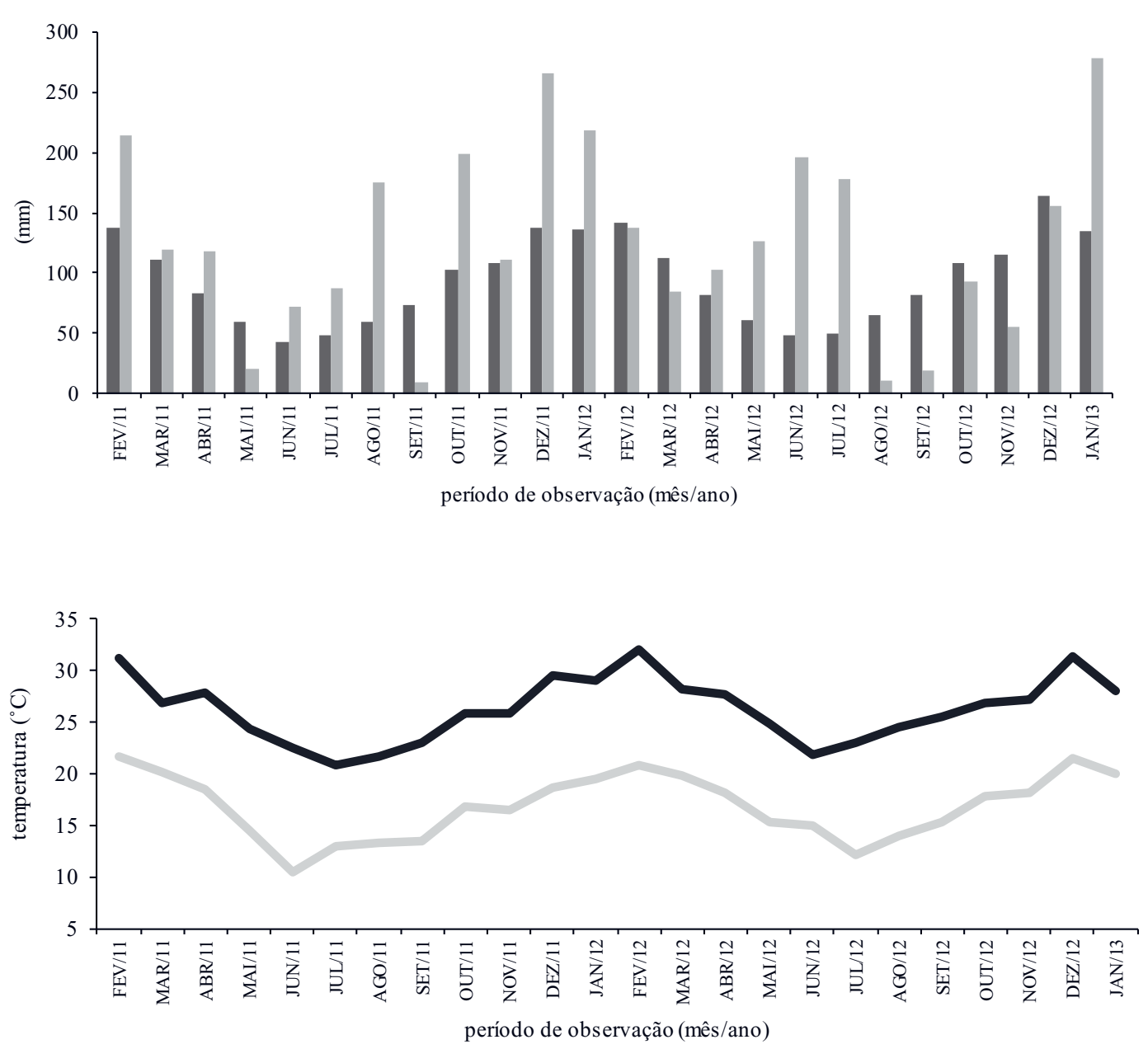

Figura 1. Precipitação e evapotranspiração (ETP) acumuladas durante o mês, e média mensal da temperatura máxima e mínima. Pariquera-Açu, SP, 2011/2012/2013. Fonte: CIIAGRO. a. Evapotranspiração potencial acumulada, Precipitação acumulada. b. Temperatura máxima, Temperatura mínima.

Figure 1. Precipitation and evapotranspiration (ETP) accumulated during the month, and monthly averge of the maximum and minimum temperature. Pariquera-Açu, SP, 2011/2012/2013. Source: CIIAGRO. a. Evapotranspiration accumulated potential, $\square$ Precipitation accumulated . b. 
teve duração de cerca de sete meses, acontecendo de forma concomitante com a floração e continuando após o final da floração, com maior intensidade entre fevereiro e maio. Já na segunda frutificação observada, observou-se que no mês de dezembro ela ocorreu de forma mais intensa, e a presença de espatas teve sua maior intensidade em novembro. Para a espécie Bactris glaucescens cultivada no município de Miranda no Mato Grosso do Sul, Fava et al. (2011) verificaram que a floração e frutificação ocorreram simultaneamente por sete meses, com maior intensidade de produção de flores nos meses de outubro e novembro e frutificação em janeiro e fevereiro num período de estudo de 14 meses.

Pode-se observar que houve diferença entre a quantidade de cachos que apresentavam floração e aqueles com frutificação, possivelmente isso ocorreu devido a não constatação do evento de floração na data do levantamento, já que o período entre a abertura da espata e o desprendimento das flores é curto. De acordo com Mora-Urpi \& Solis (1980), acompanhando o processo de polinização da mesma espécie na Costa Rica, este período é de apenas três dias. No estudo fenológico que durou 12 meses, Vilchez et al. (2007) observaram diversas espécies de palmeiras, plantas comerciais e não comerciais na Estación Biológica La Selva na Costa Rica, e também verificaram a presença de mais estruturas de frutificação do que de floração nas avaliações realizadas mensalmente. Isso também corrobora com o trabalho realizado por Fava et al. (2011) com as palmeiras $B$. glaucescens e Attalea phalerata.

O florescimento foi anual, com presença de espatas florais em alta sincronia no seu pico de produção, meses de novembro e março, o que ficou evidenciado pelos mais de $60 \%$ dos indivíduos encontrados nessa fenofase (figura 6a). Não se observou a presença de
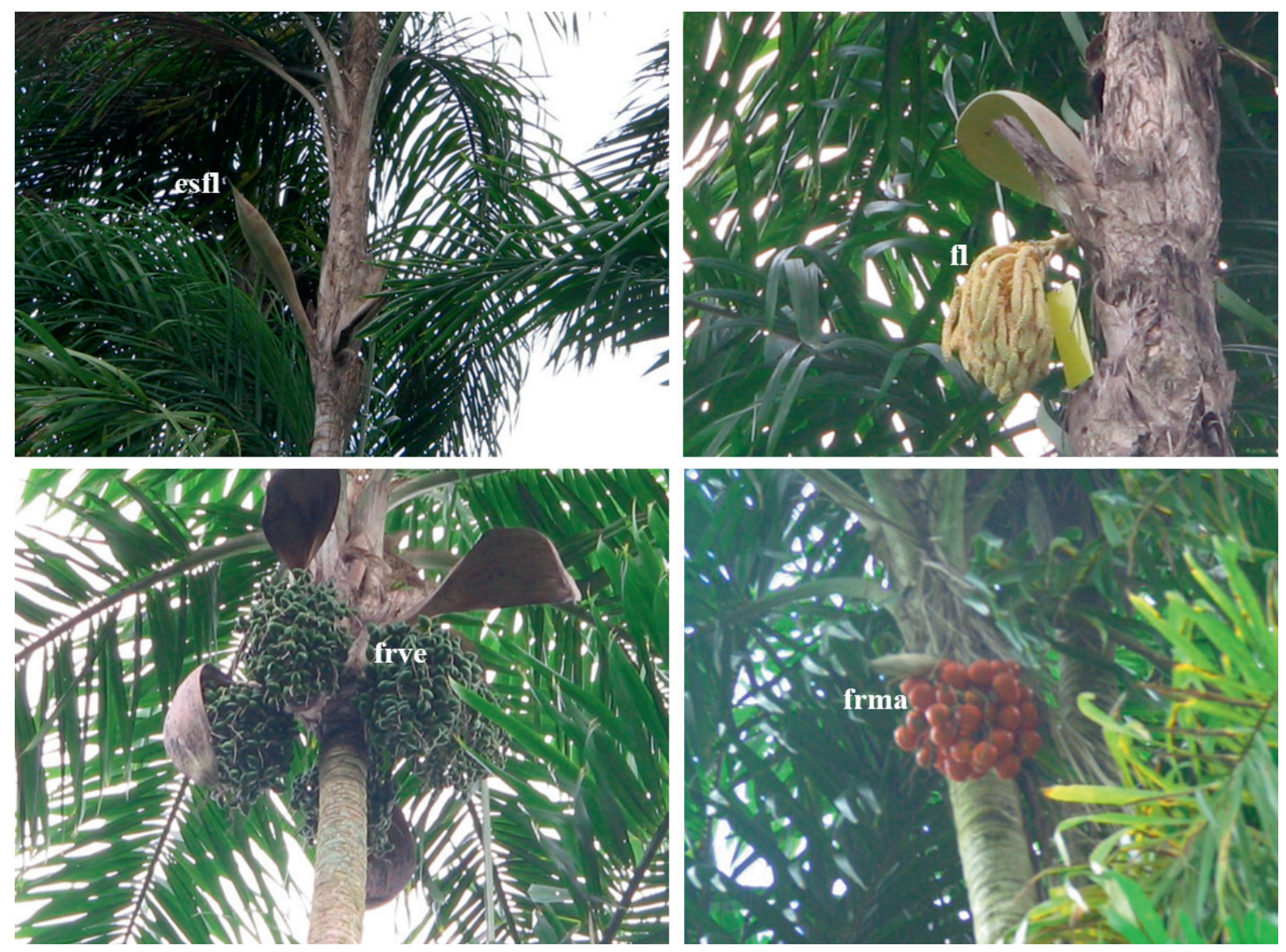

Figura 2. Matrizes de Bactris gasipaes. Pariquera-Açu, SP, 2011/2012/2013. esfl: Espata floral, fl: Floração, frve: Frutos imaturos, frma: Frutos maduros.

Figure 2. Stock plants of Bactris gasipaes. Pariquera-Açu, SP, 2011/2012/2013. esfl: Floral spathe; fl: Flowering; frve: Immature fruit; frma: Mature fruit. 
espatas durante os meses que tiveram as menores temperaturas do ano, julho e agosto. A floração, apresentou intensidade máxima nos meses de fevereiro e março em 2012, sendo pouco sincrônico. No ano de 2012 apresentou alta sincronia no mês de dezembro, diferenciando do ano de 2011. Verificou-se também que os picos de florescimento ocorreram em meses com alta precipitação e temperatura.

De acordo com Begnini et al. (2013), espécies tropicais que florescem acompanhando a precipitação, podem apresentar "manchas" de diferentes períodos de floração (assincronia) na própria espécie ao longo de uma paisagem. Ferreira (2005) por sua vez observou outro comportamento em Manaus no Amazonas, onde a floração teve início em pleno período de estiagem, por volta do mês de agosto e prolongou-se até o mês de novembro, o que corrobora com a descrição feita por Lorenzi (2002).
Os picos de frutificação ocorreram no mês de março, com mais de $90 \%$ dos indivíduos observados produzindo cachos com frutos imaturos nos dois anos, apresentando assim alta sincronia. Houve diminuição da presença dessa fenofase com o decorrer dos meses, cessando a produção de frutos imaturos de setembro a novembro. A frutificação no final do período chuvoso e durante a estação seca garante com que estes diásporos amadureçam e sejam dispersos no começo das chuvas, que seria a época ideal de germinação (Oliveira 1998).

Já a presença de infrutescências maduras deu-se durante seis meses por ano, com alto sincronismo no período de pico, maio a julho de 2011 e baixo sincronismo no ano de 2012. Tal fato diferencia-se do relatado por Ferreira \& Santos (1992), que observaram a presença de frutos maduros durante o período de chuvas de dezembro a março na Amazônia Central do Brasil. Diferentemente relataram Arco-Verde \&
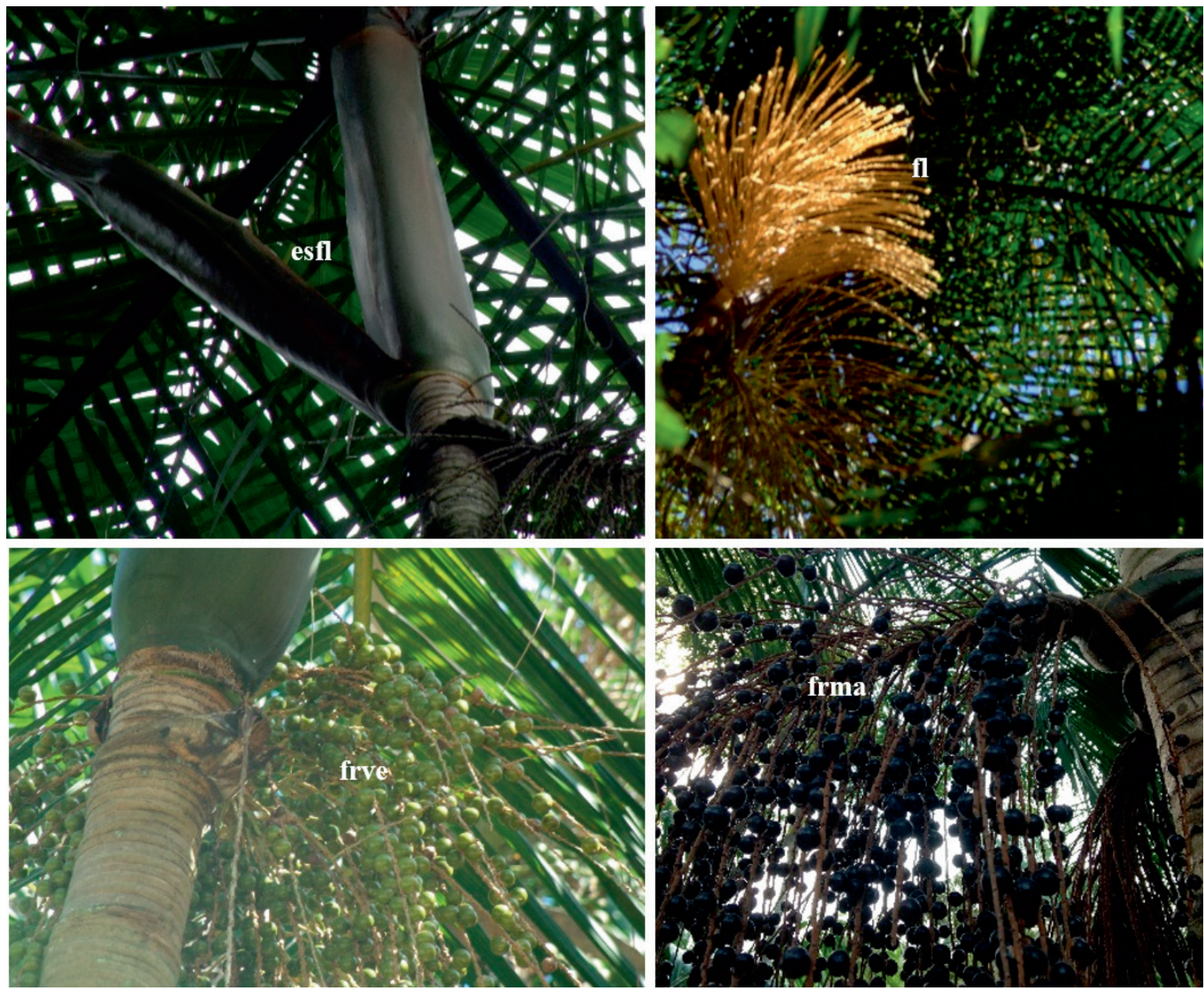

Figura 3. Matrizes de Euterpe edulis. Pariquera-Açu, SP, 2011/2012/2013. esfl: Espata floral, fl: Floração, frve: Frutos imaturos, frma: Frutos maduros.

Figure 3. Plants of Euterpe edulis. Pariquera-Açu, SP, 2011/2012/2013. esfl: Floral spathe, fl: Flowering, frve: Immature fruit, frma: Mature fruit. 
Mourão Júnior (2004), pois realizaram colheitas semanais de cachos de pupunhas entre os meses de junho e dezembro em Roraima.

Bovi (1998) por sua vez afirma que a frutificação de B. gasipaes ocorre de dezembro a maio, enquanto Lorenzi (2002) estende essa fenofase até julho. Mantovani \& Morellato (2000) afirmam que fatores como localização, idade e características genéticas intrínsecas aos indivíduos, além das condições climáticas, podem estar associadas a essas diferenças na ocorrência dos eventos reprodutivos de palmeiras.

Com relação as folhas, se observou que no mês que precedeu o início da visualização das espatas florais, setembro e outubro, a emissão daquelas foi
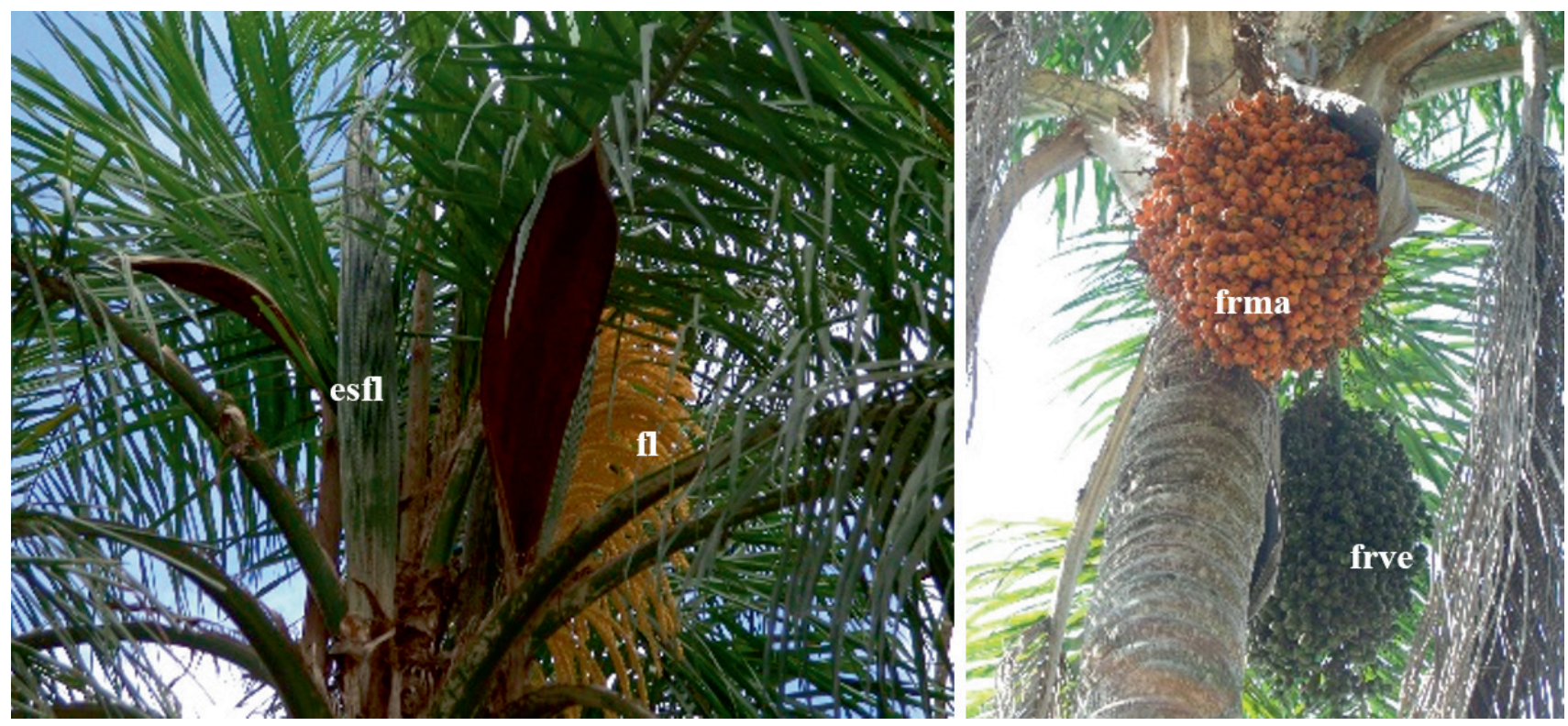

Figura 4. Matrizes de Syagrus romanzoffiana. Pariquera-Açu, SP, 2011/2012/2013. esfl: Espata floral, fl: Floração, frve: Frutos imaturos, frma: Frutos maduros.

Figure 4. Plants of Syagrus romanzoffiana. Pariquera-Açu, SP, 2011/2012/2013. esfl: Floral spathe, fl: Flowering, frve: Immature fruit, frma: Mature fruit.

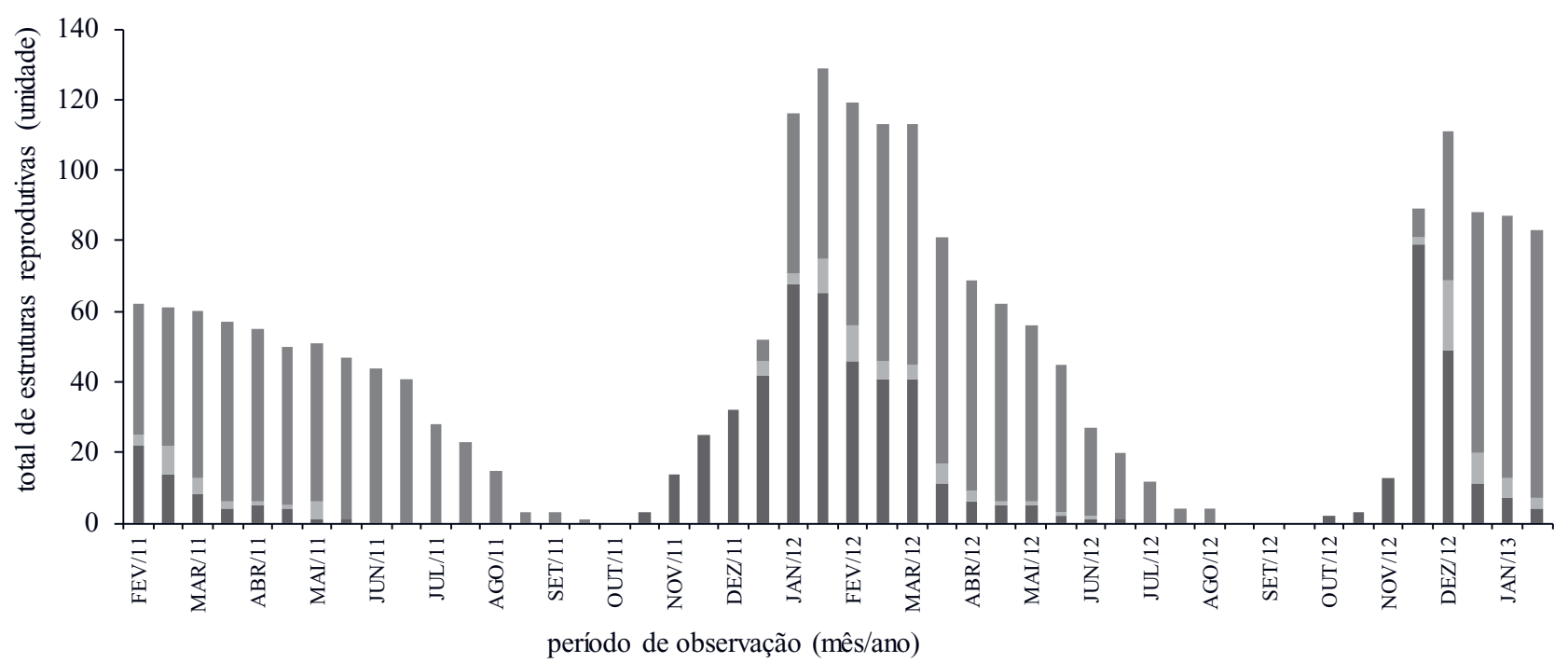

Figura 5. Número total de estruturas reprodutivas (espata floral, floração e frutificação) em 15 plantas matrizes de Bactris gasipaes Kunth. Pariquera-Açu, SP, 2011/2012/2013. Frutificação, — Floração, Espata.

Figure 5. Total number of reproductive structures (floral sheath, flowering and fruiting) in 15 plants of Bactris gasipaes.

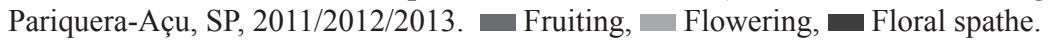




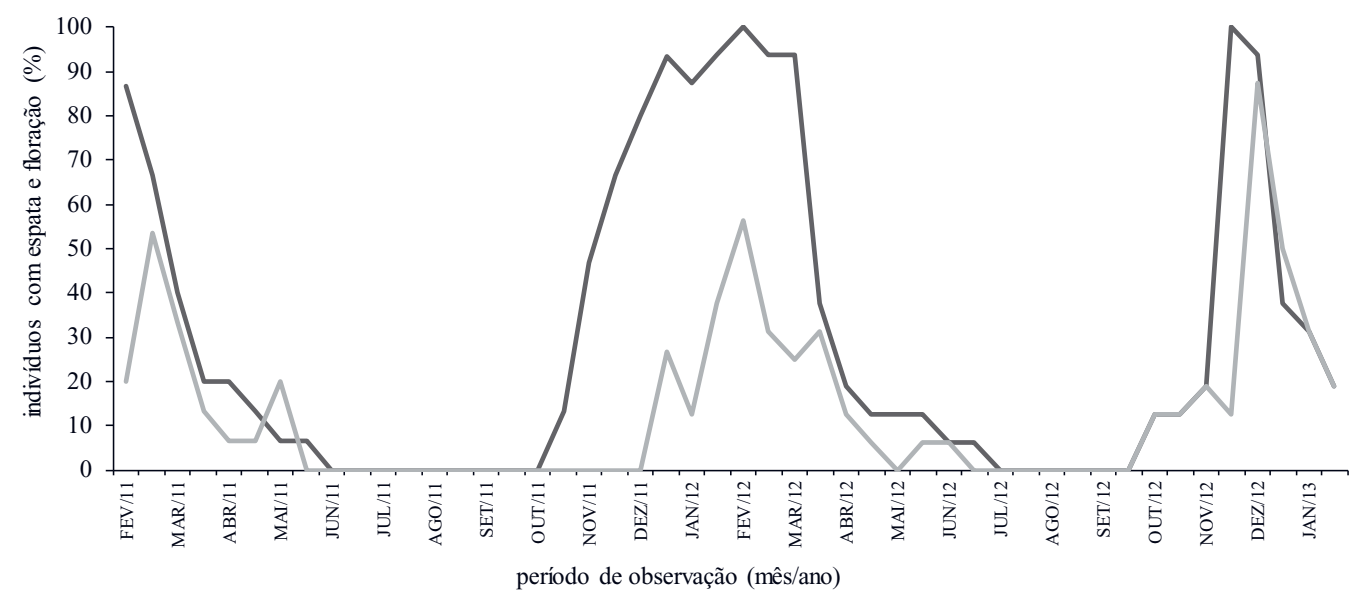

b

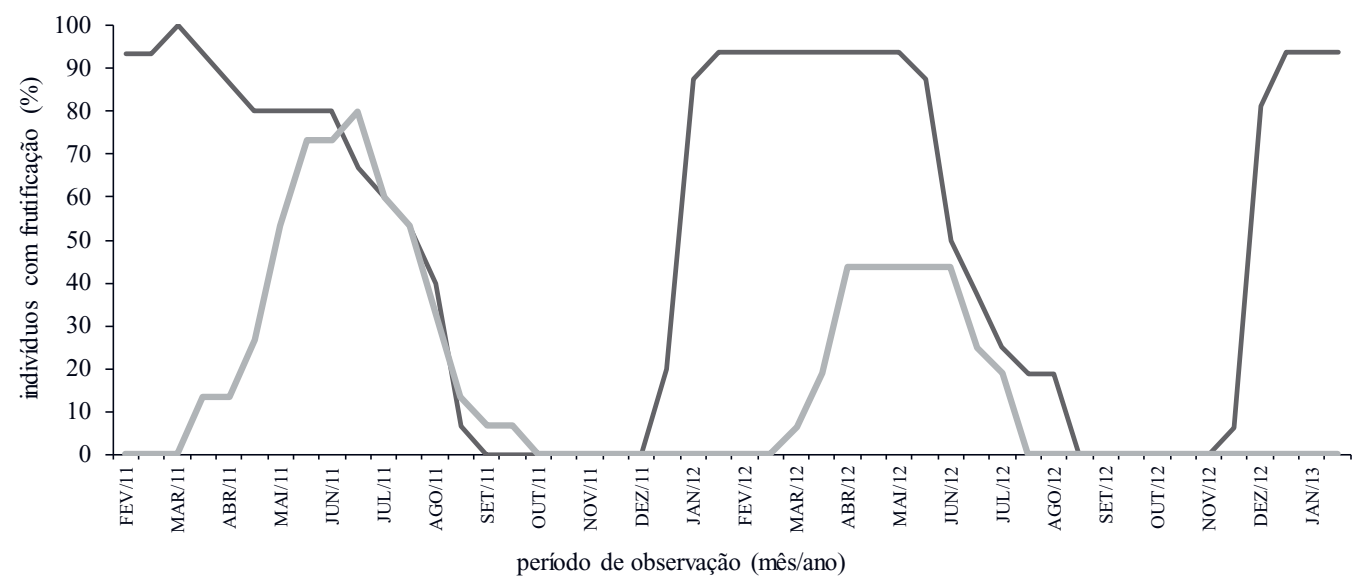

c

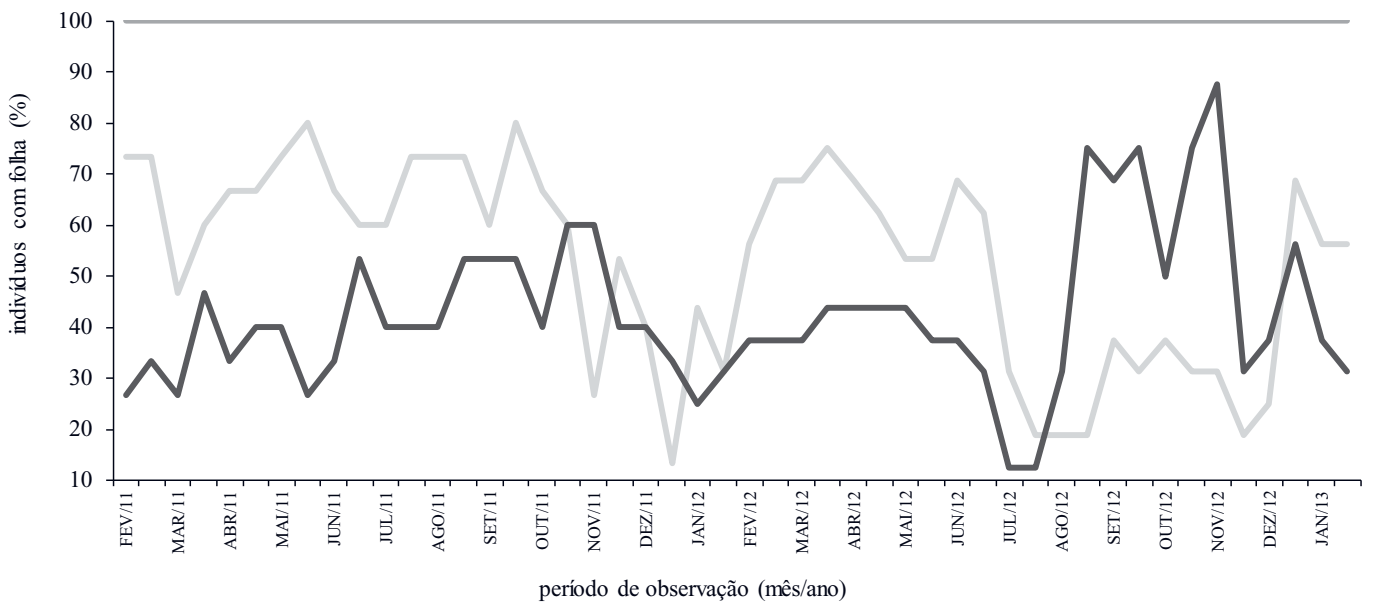

Figura 6. Porcentagem de indivíduos da população de 15 matrizes de Bactris gasipaes Kunth. que apresentam eventos fenológicos de floração (a), frutificação (b) e mudança foliar (c). Pariquera-Açu, SP, 2011/2012/2013. a. — Espata, _ Floração. b. — Cacho com frutos verdes, Cacho com frutos maduros. c. Folha nova Folha madura, Folha velha.

Figure 6. Percentage of individuals in the population of 15 plants of Bactris gasipaes Kunth. presenting phenology of flowering (a), fruiting (b) and leaf change events. Pariquera-Açu, SP, 2011/2012/2013. a. fruit green, Ripe fruit clusters. $\mathrm{c}$ New leaf, 
mais intensa, simultaneamente ao que ocorreu com a queda de folhas velhas. Mora Urpí (1981) defende que uma pupunheira pode produzir tantas inflorescências quantas forem as suas folhas. Em palmeiras, os estipes monopodiais crescem continuamente a partir de um único meristema e produzem novas folhas sequencialmente, com uma também sequencial morte e queda das folhas velhas (Corner 1966), pois, de acordo com De Steven et al. (1987), há direta associação entre as gemas das inflorescências e o desenvolvimento de folhas.

Fenologia de Euterpe edulis - As matrizes de E. edulis tiveram pouca atividade reprodutiva durante os períodos mais frios de cada ano, julho a agosto (figura 7). Logo após, em setembro, iniciou-se a emissão de espatas florais, ocorrendo o pico de intensidade nos meses de outubro e novembro, sendo considerado portanto, sazonal e concentrado. Quanto à floração, também ocorreu como um evento singular anual, apresentando pico em novembro.

Pôde-se observar que os picos de intensidade ocorreram sequencialmente, ou seja, primeiramente da espata, depois a floração e finalizando com o da frutificação. Além disso, a intensidade de um período reprodutivo para outro foi diferenciada, sendo que de outubro de 2011 a maio de 2012 apresentou atividade reprodutiva bem mais elevada do que os outros períodos avaliados.

Houve baixo sincronismo para as fenofases de espata floral e floração; seus picos ocorreram, em outubro e novembro, respectivamente (figura 8a). O florescimento assincrônico favorece a distribuição da maturação de frutos durante maior período, no entanto, pode restringir o fluxo gênico entre plantas (Reis et al. 1996). Isso pode ocorrer devido a diminuição da taxa de cruzamento, já que o fluxo gênico em populações naturais é influenciado pelo número de indivíduos que apresentam potencial de cruzamento, o que representa o tamanho efetivo da população (Sebbenn 2002). Para Castro et al. (2007), o maior percentual de indivíduos de E. edulis estudados no Parque Estadual da Ilha do Cardoso, que também se situa na região do Vale do Ribeira (SP), em floração foi no mês de novembro, contudo foi altamente sincrônica.

A ocorrência de inflorescência (espata floral e floração) deu-se de agosto a dezembro, diferentemente do constatado por Costa et al. (1997), trabalhando na Reserva Ecológica de Macaé de Cima, Nova Friburgo (RJ), onde a floração do palmiteiro ocorreu mais cedo, entre julho e outubro. Já Calvi \& Piña-Rodrigues (2005) estudando uma área em Miguel Pereira no estado do Rio de Janeiro, verificaram que o período de florescimento da espécie em questão é entre novembro

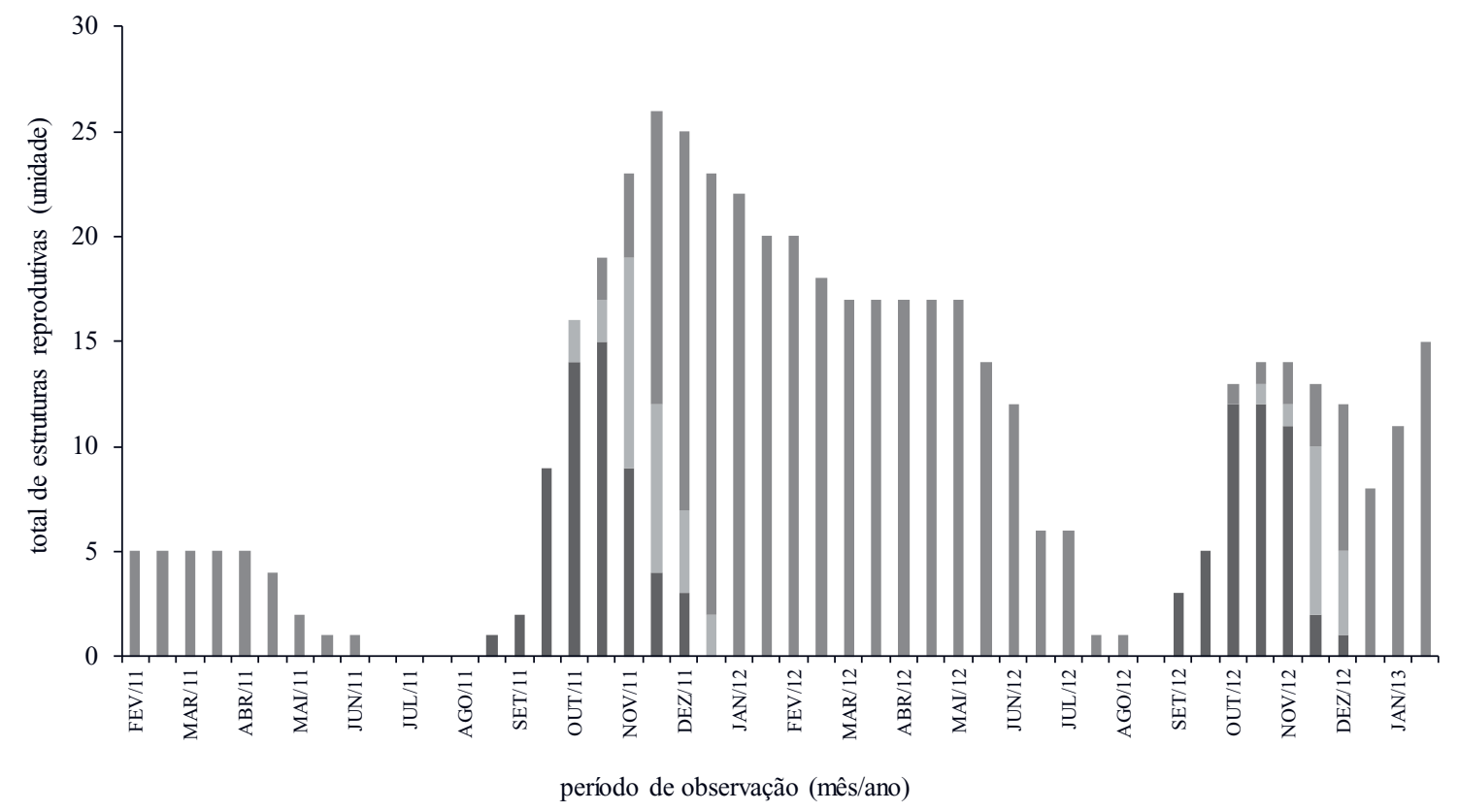

Figura 7. Número total de estruturas reprodutivas (espata floral, floração e frutificação) em 15 indivíduos adultos de Euterpe edulis em Pariquera-Açu, SP, 2011/2012/2013. Frutificação, — Floração, ש Espata.

Figure 7. Total number of reproductive structures (floral spathe, flowering and fruiting) in 15 plants of Euterpe edulis. PariqueraAçu, SP, 2011/2012/2013. Fruiting, Flowering, Eloral spathe. 

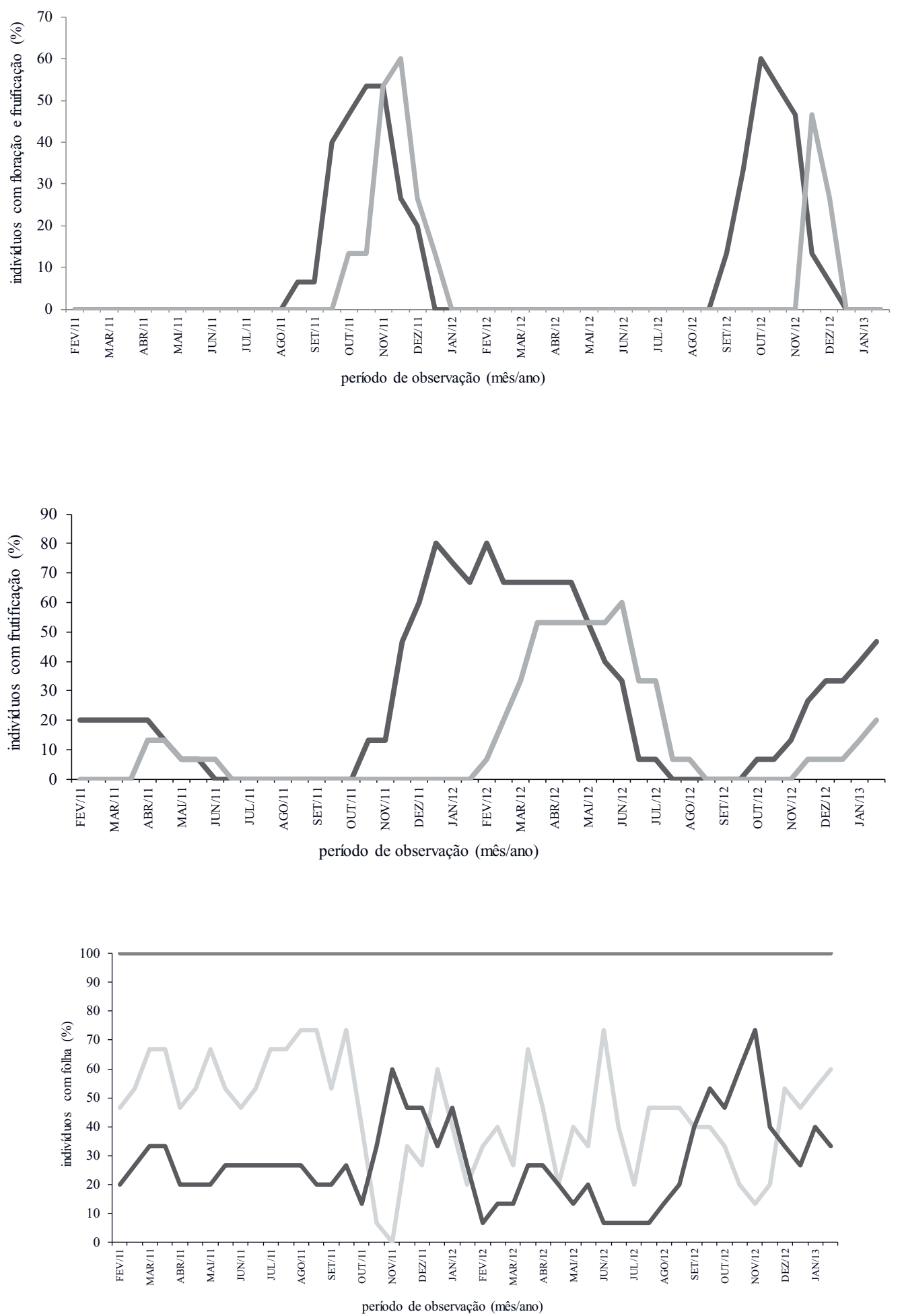

Figura 8. Porcentagem de indivíduos da população de 15 adultos de Euterpe edulis que apresentaram eventos fenológicos de floração (a), frutificação (b) e mudança foliar (c) em Pariquera-Açu, SP, 2011/2012/2013. a. Espata, Floração. b. Cacho com frutos verdes, Cachos com frutos maduros. c. Folha nova Folha madura, Folha velha.

Figure 8. Percentage of individuals in the population of 15 plants of Euterpe edulis presenting phenology of flowering (a), fruiting (b) and leaf change events. Pariquera-açu, SP, 2011/2012/2013. a Floral spathe, Flowering. b. Ripe fruit green, Ripe fruit clusters. $c$ New leaf, Mature leaf, Old leaf. 
e março, o que também foi observado por Fisch et al. (2000) em Pindamonhangaba, estado de São Paulo.

Quanto a avaliação dos frutos imaturos, verificou-se que o grau de sincronismo foi elevado para os indivíduos observados, correspondendo a $80 \%$, em seu pico de produção - entre dezembro de 2011 e fevereiro de 2012. Diferentemente, ocorreu com a fenofase de frutos maduros, que se comportou como um evento fenológico assincrônico. Reis et al. (2000), bem como Mantovani \& Morellato (2000), estudando a mesma espécie em um fragmento de Floresta Atlântica em São Paulo, também encontraram resultados semelhantes.

Comportamento semelhante foi visto em Euterpe oleracea Mart., que apesar de florescer durante todo o ano, tem pico na estação mais chuvosa, e frutificação na seca (Jardim \& Kageyama 1994).

Quanto à mudança foliar (figura 8c), ocorreram simultaneamente todas as fenofases vegetativas durante o período de observação, caracterizando o aspecto perenifólio da espécie. Os indivíduos observados tiveram folhas velhas durante todo o período de observação com baixo sincronismo, exceto em novembro/2012. A maior quantidade de matrizes apresentando essa fenofase ocorreu nos meses de novembro, coincidindo com o período com menos indivíduos apresentando emissão de folhas novas. O contrário foi observado por Bencke \& Morellato (2002) observaram em Ubatuba (SP) onde tais fenofases ocorreram de forma constante.

Fenologia de Syagrus romanzoffiana - O padrão fenológico de Syagrus romanzoffiana foi anual, tal como foi classificado por Newstrom et al. (1994). Suas matrizes apresentaram atividade reprodutiva em todo período de observação, com intensidade diferenciada entre um período reprodutivo e outro. Verificando-se ainda, picos de intensidade ocorrendo sequencialmente, ou seja, primeiramente espata, depois a floração e finalizando com a frutificação (figura 9).

$\mathrm{Na}$ época do ano com temperaturas mais baixas, houve pico de intensidade de espatas florais, chegando a $100 \%$ das plantas nessa fenofase, demonstrando alto sincronismo (figura 10a). A primeira floração observada teve baixo sincronismo, e ocorreu entre os meses de junho e dezembro, com pico de intensidade em setembro. Já no estado do Paraná, esse evento foi registrado no período de setembro a março (Rego et al. 2011), enquanto em Santa Catarina, se restringiu aos meses de dezembro e janeiro (Begnini et al. 2013).

Já com relação ao período de frutificação, o evento foi registrado nos meses de novembro de 2011 e fevereiro de 2012, com a maioria das plantas nessa fenofase (figura 10b). Begnini et al. (2013), registraram menor intensidade de tal evento entre outubro e dezembro, e mencionam uma possível correlação com a temperatura.

A presença de frutos imaturos se deu em todos os meses de frutificação, tendo alta sincronia de outubro de 2011 a março de 2012, chegando a 92,9\% dos indivíduos estudados. Os frutos maduros se desenvolveram de fevereiro de 2011 a abril de 2011 de forma pouco sincrônica e de fevereiro de 2012 a junho de 2012 com alta sincronia.

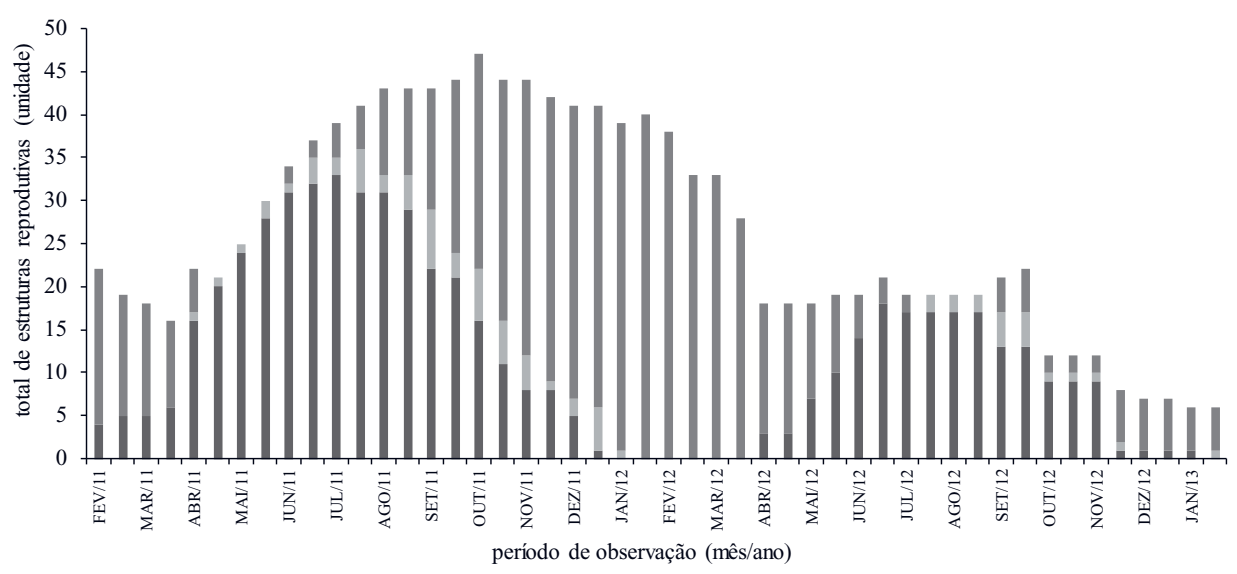

Figura 9. Número total de estruturas reprodutivas (espata, floração e frutificação) em 15 indivíduos adultos de Syagrus romanzzoffiana. Pariquera-Açu, SP, 2011/2012/2013. Frutificação, — Floração, ש Espata.

Figure 9. Total number of reproductive structures (floral sheath, flowering and fruiting) in 15 plants of Syagrus romanzoffiana. Pariquera-Açu, SP, 2011/2012/2013. Fruiting, $\square$ Flowering, $\square$ Floral spathe. 

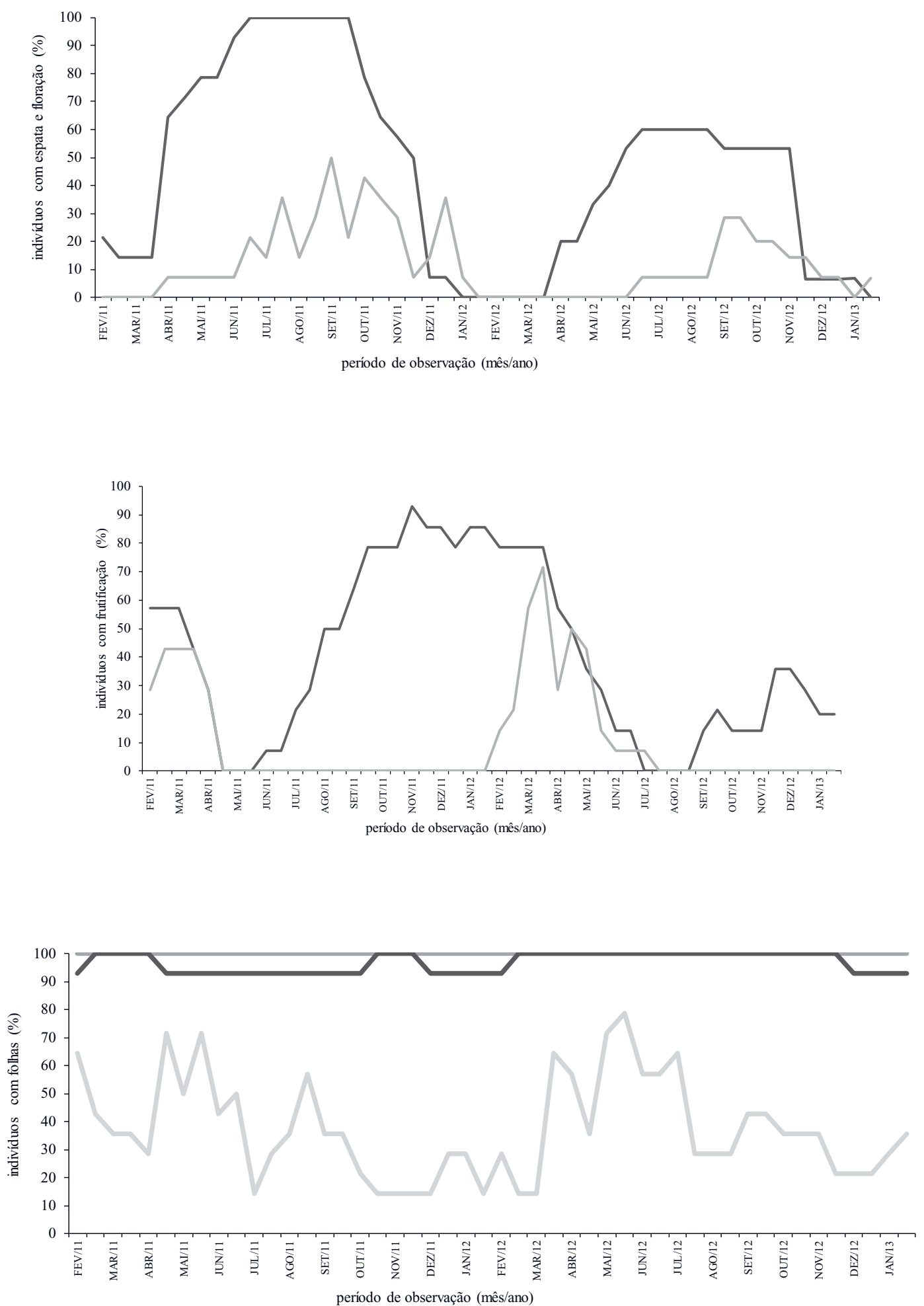

Figura 10. Porcentagem de indivíduos da população de 15 adultos de Syagrus romanzoffiana que apresentaram eventos fenológicos de floração (a), frutificação (b) e mudança foliar (c). Pariquera-Açu, SP, 2011/2012/2013. a. Espata, Floração. b. Cacho com frutos verdes, Cacho com frutos maduros. c. Folha nova, Folha madura, Folha velha.

Figure 10. Percentage of individuals in the population of 15 plants of Syagrus romanzoffiana presenting phenology of flowering (a), fruiting (b) and leaf change events. Pariquera-Açu, SP, 2011/2012/2013. a. Floral spathe, Flowering. b. Ripe fruit green, Ripe fruit clusters. $\mathrm{c}$ New leaf, 


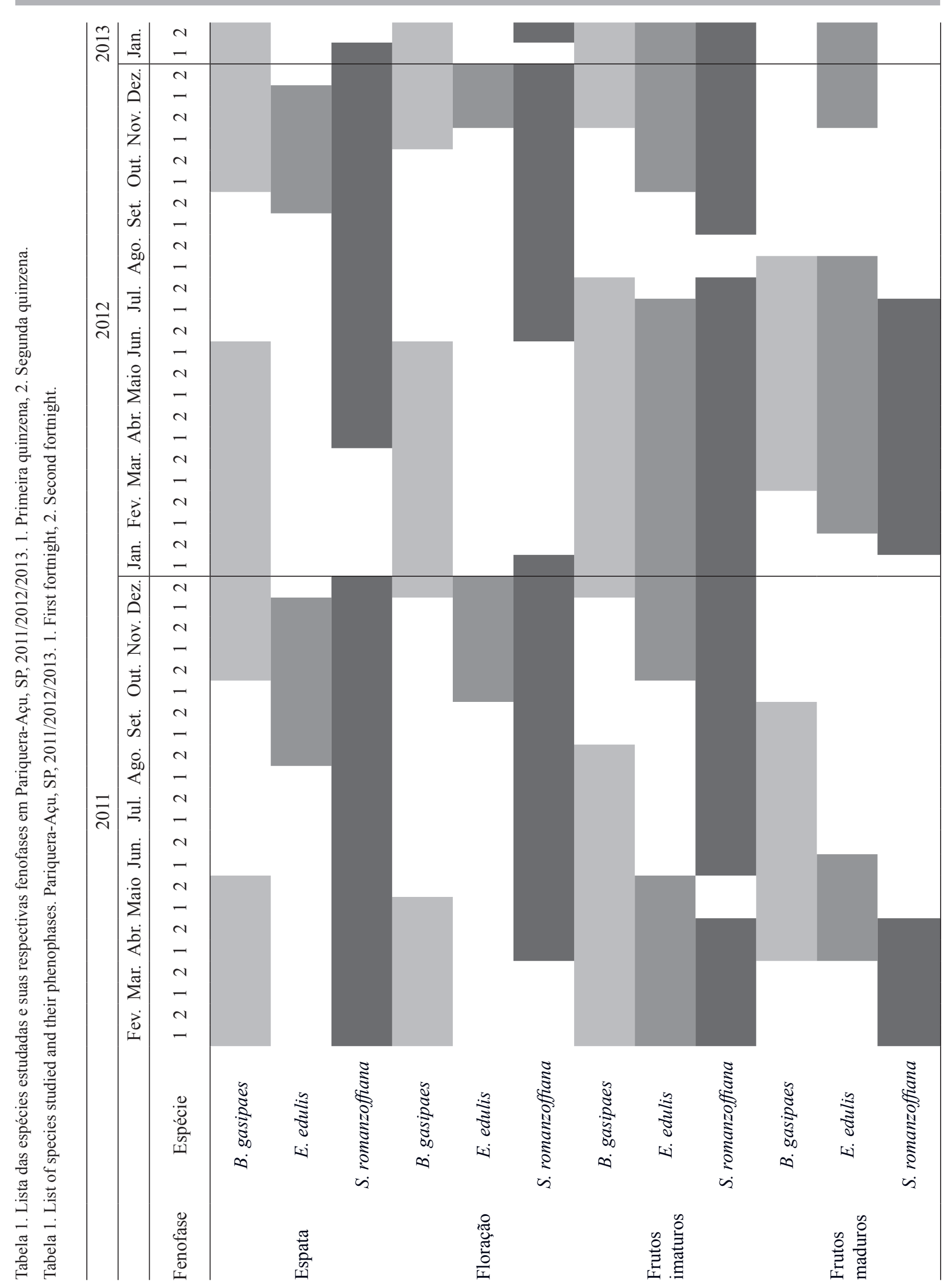




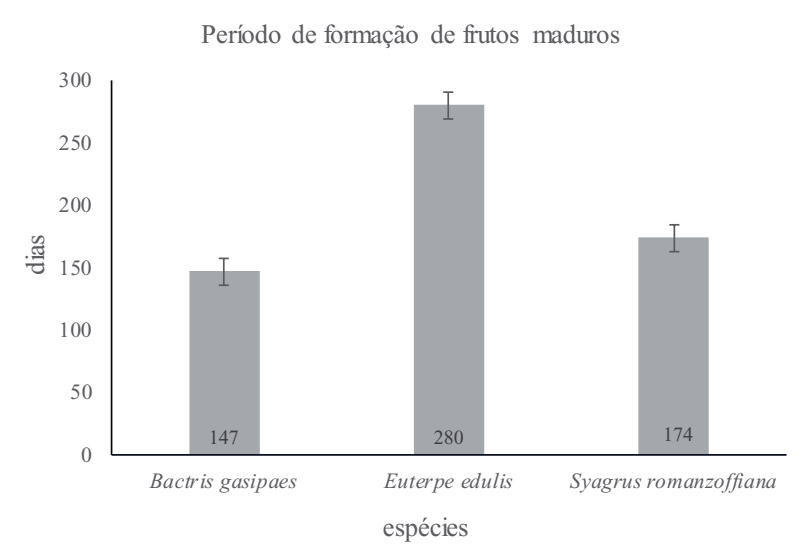

Figura 11. Tempo decorrido da abertura da espata floral até a formação de frutos completamente maduros em 12 estruturas reprodutivas em diferentes plantas em três espécies de palmeiras. Pariquera-Açu, SP, 2012.

Figure 11. Average time between the opening of floral sheath until the formation of fully ripe fruit in 12 reproductive structures in different plants in three species of palm trees. Pariquera-Açu, SP, 2012.

É possível variações nesse evento com intensidade de produção nos meses de fevereiro e março, enquanto os frutos maduros podem ter picos de produção nos meses de maio, junho e julho (Begnini et al. 2013).

No que se refere às folhas velhas e maduras houve alto sincronismo e foram constantes em todo período de estudo, caracterizando a espécie como perenifólia (figura 10c). As folhas novas ocorreram entre abril e junho, tendo alta sincronia, sendo este o início do período da formação das espatas florais. De acordo com Biondi et al. (2007) a produção de inflorescências tende a suceder os períodos de maior produção foliar.

Comparando as três espécies de palmeiras estudadas e suas respectivas fenofases reprodutivas (tabela 1), observou-se que sempre alguns indivíduos apresentaram atividade reprodutiva. As três espécies produziram flores ao longo do ano, contudo o pico de produção de espatas florais e de floração aconteceu em diferentes meses. A produção de frutos, tanto imaturos como maduros, ocorreu durante todo o ano, sempre com pelo menos um indivíduo de alguma das espécies com frutificação, com maior intensidade em meses de temperatura elevada.

Os períodos de formação de fruto variaram entre as espécies (figura 11), sendo E. edulis a que requereu maior tempo para totalizar o processo, com uma média de 280 dias. Já B. gasipaes necessitou de quase a metade do tempo exigido por E. edulis, 147 dias, enquanto Syagrus romanzoffiana levou 174 dias.

Finalmente, pode se afirmar que a fenologia das espécies estudadas, ocorreu como um evento singular anual, com variações na sua intensidade reprodutiva e ao longo do período.

\section{Agradecimentos}

Os autores agradecem ao Pólo Regional de Desenvolvimento Sustentável dos Agronegócios do Vale do Ribeira - APTA/SAA-SP e seus funcionários, a permissão e auxilio para as colheitas de frutos e coleta de dados; ao Centro Integrado de Informações Agrometeorológicas (CIIAGRO), pelo fornecimento dos dados meteorológicos; ao CNPq, pela bolsa concedidas a Cláudio José Barbedo (produtividade em pesquisa).

\section{Literatura citada}

Alencar, J. C. 1994. Fenologia de cinco espécies arbóreas tropicais de Sapotaceae correlacionada a variáveis climáticas na reserva Ducke, Manaus, AM. Acta Amazonica 24:161-182.

Antunes, N. \& Ribeiro, J.F. 1999. Aspectos fenológicos de seis espécies vegetais e matas de galeria do distrito federal. Pesquisa Agropecuária Brasileira. Brasília 34: 1517-1527.

Arco-Verde, M. F. \& Mourão Júnior, M. 2004. Época de produção da pupunha (Bactris gasipaes) como componente de sistemas agroflorestais em Roraima. Boletim Técnico 12 - EMBRAPA.

Begnini, R.M., Silva, F.R. \& Castellani, T.T. 2013. Fenologia reprodutiva de Syagrus romanzoffiana (Cham.) Glassman (Arecaceae) em Floresta Atlântica no sul do Brasil. Biotemas 4: 53-60.

Bencke, C.S.C. \& Morellato, L.P.C. 2002. Estudo comparativo da fenologia de nove espécies arbóreas em três tipos de Floresta Atlântica no Sudeste do Brasil. Revista Brasileira de Botânica 2: 237-248.

Bernacci, L.C., Martins, F.R. \& Santos, F.A.M. 2006. Dinâmica populacional da palmeira nativa jerivá, Syagrus romanzoffiana (Cham.) Glassman, em um fragmento florestal no sudeste do Brasil. Disponível em http://www. infobibos.com/Artigos (acesso em 20-VIII-2013).

Biondi, D., Leal, L. \& Batista, A.C. 2007. Fenologia do florescimento e frutificação de espécies nativas dos Campos. Acta Scientiarum Biological Sciences 29: 269-276.

Bovi, M.L.A. 1998. Palmito Pupunha: Informações básicas para cultivo. Boletim Técnico $n^{\circ}$ 173. Campinas, Instituto Agronômico.

Calvin, G.P. \& Piña-Rodrigues, F.C.M. 2005. Fenologia e produção de sementes de Euterpe edulis - Mart. Em trecho de floresta de altitude no município de Miguel Pereira - RJ. Revista Universidade Rural 25: 22-40.

Castro, E.R., Galetti, M. \& Morellato, L.P.C. 2007. Reproductive phenology of Euterpe edulis (Arecaceae) along a gradient in the Atlantic rainforest of Brazil. Australian Journal of Botany 55: 725-735. 
Corner, E.J.H. 1966. The Natural History of Palm. Weidenfeld and Nicolson, London.

Costa, M.L.M.N., Andrade, A.C.S. \& Pereira, T.S. 1997. Fenologia de espécies arbóreas em floresta Montana na Reserva Ecológica de Macaé de Cima. In: H.C. Lima, R.R. Guedes-Bruni, R.R. (ed.). Serra de Macaé de Cima: Diversidade florística e conservação em Mata Atlântica. Rio de Janeiro: Instituto de Pesquisas Jardim Botânico do Rio de Janeiro. Rio de Janeiro, pp. 169-186.

D'Eça-Neves, F.F. \& Morellato, L.P.C. 2004. Métodos de amostragem e avaliação utilizados em estudos fenológicos de florestas tropicais. Acta Botanica Brasilica 18: 99-108.

De Steven, D., Windsor, D.M., Putz, F.E. \& De Leon, B. 1987. Vegetative and reproductive phenologies of a palm assemblage in Panama. Biotropica 19: 342-356.

Fava, W.S., Covre, W.S. \& Sigrist, M.R. 2011. Attalea phalerata and Bactris glaucescens (Arecaceae, Arecoideae): Phenology and pollination ecology in the Pantanal, Brazil. Flora: Morphology, Distribution, Functional Ecology of Plants 206: 575-584.

Ferreira, S.A.N. 2005. Pupunha, Bactris gasipaes Kunth in: I.D.K. Ferraz \& J.L.C. Camargo (eds.). Manual de Sementes da Amazônia. Fascículo 5, Manaus.

Ferreira, S.A.N. \& Santos, L.A. 1992.Viabilidade de sementes de pupunha (Bactris gasipaes Kunth). Acta Amazonica 22: 303-307.

Fisch, S.T., Nogueira, J.R.L.R. \& Mantovani, W. 2000. Fenologia reprodutiva de Euterpe edulis Mart. na Mata atlântica (Reserva Ecológica do Trabiju, Pindamonhangaba-SP). Revista de Biociências 6: 31-37.

Frankie G.W., Baker, H.G. \& Opler, A.P. 1974. Comparative phenological studies of trees in tropical wet and dry forests in the low lands of Costa Rica. Journal of Applied Ecology 62: 881-919.

Fournier, L.A. 1974. Um método cuantitativo para la medición de características fenológicas em árboles. Turrialba 24: 422-423.

Galetti, M. \& Aleixo, A. 1998. Effects of palm heart harvesting on avian frugivores in the Atlantic rain forest of Brazil. Journal of Applied Ecology 35: 286-293.

Galetti, M., Paschoal, M. \& Pedroni, F. 1992. Predation on palms nuts (Syagrus romanzoffiana) by squirrels (Sciurus ingrami) in south-east Brazil. Journal of Tropical Ecology 8: 121-123.

Galetti, M., Donatti, C.I., Pires, A.S. \& Jordano, P. 2006. Seed survival and dispersal of an endemic Atlantic forest palm: the combined effects of defaunation and forest fragmentation. Botanical Journal of the Linnean Society 151: 141-149.

Henderson, A., Fischer, B., Scariot, A., Pacheco, M.A.W. \& Pardini, R. 2000. Flowering phenology of a palm community in a central Amazon Forest. Brittonia 52: 149-159.
Janzen, D.H. 1976. Seeding patterns of tropical trees. In: P.B. Tommilinson \& M.H. Zimmermann (eds.). Tropical trees as living systems. Cambridge: Cambridge University, pp. 88-128.

Jardim, M. A. G. \& Kageyama, P. Y. 1994. Fenologia de floração e frutificação em população natural de açaizeiro (Euterpe oleracea Mart.) no estuário amazônico. Instituto de Pesquisas e Estudos Florestais 47: 62-65.

Lieth, H. Purposes of a phenology. 1974. In: Phenology and seasonality modeling. Berlim: Springer - Verlag, pp. 3-19.

Lorenzi, H. 2002. Árvores brasileiras - Manual de identificação e cultivo de plantas arbóreas nativas do Brasil. Nova Odessa.

Mantovani, A. \& Morellato, L.P.C. 2000. Fenologia da floração, frutificação, mudança foliar e aspectos da biologia floral do palmiteiro Euterpe edulis (Arecaceae). Sellowia, 49: 23-38.

Mora-Urpí, J. 1981. El ciclo de floración en pejibaye (Bactris gasipaes H.B.K.) y su posible manejo agronomico. Agronomia Costarricense 5: 115-119.

Mora-Urpí, J. \& Solis, E. 1980. Polinización en Bactris gasipaes H.B.K. (Palmae). Revista de Biologia Tropical 28: 153-174.

Morellato, L.P.C., Leitão-Filho, H.F., Rodrigues, R.R., \& Joly, C.A. 1990. Estratégias fenológicas de espécies arbóreas em floresta de altitude na Serra do Japi, Jundiaí, SP. Revista Brasileira de Biologia 50:149-162.

Morellato, L.P.C., Rodrigues, R.R., Leitão-Filho, H.F. \& Joly, C.A. 1989. Estudo comparativo de espécies arbóreas de floresta de altitude e floresta mesófila semidecídua na Serra do Japi, Jundiaí, São Paulo. Revista Brasileira de Botânica 12: 85-98.

Newstrom, L.E., Frankie, G.W. \& Baker, H.G. 1994. A new classification for plant phenology based on flowering patterns in lowland tropical forest trees at $\mathrm{La}$ Selva, Costa Rica. Biotropica 26: 141-159.

Oliveira, P.E., Sano, S.M., \& Almeida, S.D. 1998. Fenologia e biologia reprodutiva das espécies de cerrado. Cerrado: Ambiente e Flora 288-556.

Ranieri, B.D., Pezzini, F.F., Garcia, Q.S., Chautems, A. \& França, M.G.C. 2012. Testing the regeneration niche hypothesis with Gesneriaceae (Tribe Sinningiae) in Brazil: Implications for the conservation of rare species. Austral Ecology 37: 125-133.

Rathcke, B. \& Lacey, E.P. 1985, Phenological patterns of terrestrial plants. Ann. Rev. Ecol. Syst., 16: 179-214.

Rego, G.M., Lavoranti, O.J. \& Vieira, E.S.N. 2011. Fenologia reprodutiva: período de produção de sementes de jerivá. Informativo Abrates 21: 130.

Reis, A., Kageyama, P.Y., Reis, M.D. \& Fantini, A. 1996. Demografia de Euterpe edulis Martius (Arecaceae) em uma floresta ombrófila densa montana. Blumenau (SC). Sellowia 45: 13-45. 
Reis, A. \& Kageyama, P.Y. 2000. Dispersão de sementes do palmiteiro (Euterpe edulis Martius - Palmae). In: M.S. Reis, \& A. Reis (eds.). Euterpe edulis Martius (Palmiteiro): biologia, conservação e manejo. Sellowia 45: 60-92.

Reis, M.S., Guerra, M.P., Nodari, R.O., Ribeiro, R.J. \& Reis, A. 2000. Distribuição geográfica e situação atual das populações na área de ocorrência de Euterpe edulis Martius. Sellowia 49: 324-335.
Sebben,A.M. 2002. Número de árvores matrizes e conceitos genéticos na coleta de sementes para reflorestamento com espécies nativas. Revista do Instituto Florestal de São Paulo 14: 115-132.

Vilchez, B., Chazdon, R.L. \& Alvarado, W. 2007. Fenología reproductive de las especies del dosel superior en seis sitios de la Región Huetar Norte de Costa Rica. Kuru: Revista Forestal Costa Rica 4: 1-16. 